\title{
Image fragmentations with afterimages and in binocular rivalry'
}

\author{
PETER K. SMITH 2 \\ UNIVERSITY OF CAMBRIDGE, ENGLAND
}

'Structured' and 'unstructured' fragmentations of a simple geometric figure were compared in conditions of binocular rivalry, and afterimage viewing, for ten Ss. For all subjects 'structured' fragmentations were found to be much less common and less stable in rivalry.

It has been known for some time (Pritchard, Heron \& Hebb, 1960; Bennet-Clark \& Evans, 1963; Evans \& Piggins, 1963) that when an image is more or less stabilized on the retina by prolonged voluntary fixation, use of a close-fitting contact lens, or viewing of an afterimage, the fragmentations that occur are often "structured" - that is, arcs or lines disappear as units, leaving clean-cut corners.

It was considered of interest to discover whether structured fragmentations also occurred when figures were seen in binocular rivalry with visual noise presented to the other eye.

Initial studies attempted to reproduce in the rivalry situation the results of Pritchard et al (1960). Quite different results were obtained. Structured fragmentations were very rare in rivalry. "Meaningful" figures, at either a simple or complex level of meaning, were not more stable than "unmeaningful" figures. No reports of "closure" were obtained (in contrast, a few reports of closure were obtained in afterimage viewing).

In the main experiment, the fragmentations of a simple geometric figure (Fig. 1) were examined quantitatively, to give a direct comparison between the rivalry and afterimage conditions.

\section{Method and Procedure}

The figure used (Fig. 1) was identical in both rivalry and afterimage experiments, in both cases subtending a retinal angle of $3 \mathrm{deg}$. The lines were approximately 8-1/2 min wide.

Rivalry. Ss looked into a prism stereoscope, and saw Fig. 1 in one eye, drawn in black ink on white card, and "visual noise" (a Julesz random pattern, 6 deg square) in the other. Which eye the figure was shown to, and the illuminations of both sides, was decided individually for each $S$ to give a fluctuation rate suitable for reporting, and then held constant. These factors seemed not to alter the form of the fragmentations observed. Ss fixated the center of the figure.

Afterimage viewing. This was used as an effective and simple method of stabilizing the image on the retina (Bennet-Clark \& Evans, 1963). Ss dark-2dapted for 7 min, and then fixated the center of a stencil of Fig. 1 in front of an electronic flash gun, with the same eye as observed Fig. 1 in rivalry. They observed the afterimage with both eyes closed.

In both conditions, Ss reported their observations by pressing a key which activated an electronic timer and counter. Two different instructions were used. The S was asked to hold the key down when (1) he saw an unstructured fragmentation ( $U$ ) and (2) he saw a structured fragmentation (S). "Structured" and "unstructured" have the same meaning as in, for example, Evans \& Piggins (1963). Figure 2 shows examples of unstructured fragmentations, Fig. 3 of structured fragmentations. Ss were shown these and other examples. Cases of no disappearance, or complete disappearance, of Fig. 1 were excluded from either category.

In rivalry, the instructions (1) and (2) were repeated with the visual noise stimulus removed, as a control for Troxler's effect. Out of twelve initial Ss, two were
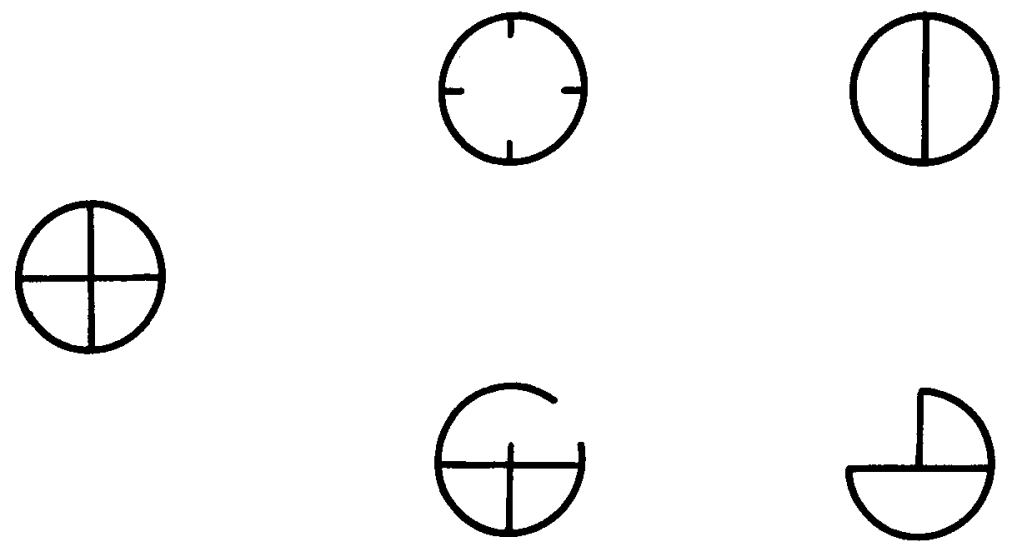

Fig. 1.

Fig. 2.

Fig. 3. 
Table 1.

\begin{tabular}{|c|c|c|c|c|c|c|c|c|}
\hline \multirow[b]{3}{*}{$\mathrm{T}(\mathrm{sec})$} & \multicolumn{4}{|c|}{ Rivalry } & \multicolumn{4}{|c|}{ Afterimage } \\
\hline & \multicolumn{2}{|c|}{$\mathrm{U}$} & \multicolumn{2}{|r|}{$S$} & \multicolumn{2}{|r|}{$\mathrm{U}$} & \multicolumn{2}{|c|}{$S$} \\
\hline & 21.6 & $(17.1)$ & 1.8 & $(1.2)$ & 8.2 & (5.9) & 12.2 & $(8.4)$ \\
\hline $\mathrm{t}(\mathrm{sec})$ & 1.71 & $(1.59)$ & 0.58 & $(0.15)$ & 1.32 & $(1.37)$ & 1.69 & (1.37) \\
\hline
\end{tabular}

rejected in this way as showing an appreciable amount of Troxler's effect.

Five trials were given for each instruction, in each condition. Each trial lasted $60 \mathrm{sec}$. Sequences of trials were randomized.

\section{Results}

Table 1 gives the average values (10 Ss, five trials each) for the total time $T$ (out of $60 \mathrm{sec}$ ), and the time per key press $t$, under each instruction. (Interquartile range of $S$ averages is in brackets.) In rivalry, structured fragmentations form only $9.6 \%$ of the total fragmentation time; for afterimage viewing, the figure is $61.0 \%$. The duration of individual structured fragmentations in rivalry is also much less $(0.6 \mathrm{sec})$ than in afterimage viewing $(1.7 \mathrm{sec})$. These results hold for every $S$, without exception. (Binomial two-tailed $p=$ $.002)$. There is no correlation between the values of $T$, or of $t$, between the two conditions. For every $S$, unstructured fragmentations greatly predominated in rivalry.

\section{Discussion}

The value of $t=0.6 \mathrm{sec}$ for structured fragmentations in rivalry should not be taken literally. The durations of fleeting and complex perceptions can only be estimated approximately. The values of $t$ obtained indicate that in rivalry, structured fragmentations are brief momentary appearances, lacking the relative stability of some such fragmentations in afterimage viewing. This is supported by Ss introspective reports, and the lack of correlation between the two conditions. The results of other experiments have suggested that the prevalence of unstructured fragmentations in rivalry is general, and not peculiar to the specific conditions used here.

This experiment, by providing a control situation -rivalry-in which predominantly unstructured fragmentations are reported, also supports the belief that the structured fragmentations reported in afterimages and stabilized images depend on perceptual rather than response mechanisms.

The form of the latter structured fragmentations suggests that they might be caused by the inactivity of units like the hypercomplex cells of Hubel \& Wiesel (1965). Since binocular rivalry almost certainly occurs in the cortex, the main result, that structured fragmentations are less common in rivalry, also suggests that the site of some afterimage fragmentations is at least rostral to the first stage of cortical analysis. Since the fragmentations of afterimages and optically stabilized images seem comparable, this accords with other evidence indicating that the disappearances of the latter depend partly on cortical mechanisms (see, e.g., Riggs \& Whittle, 1967).

\section{References}

BENNET-CLARK, H. C., \& EVANS, C. R., Fragmentation of patterned targets when viewed as prolonged after-images. Nature, 199, 1215, 1963.

EVANS, C. R., \& PIGGINS, D. J. A Comparison of the behaviour of geometrical shapes when viewed under conditions of steady fixation, and with apparatus for producing a stabilized retinal image. Brit. J. Physiol. Optics, 20, No. 4, 1963.

HUBEL, D. H., \& WIESEL, T. N. Receptive fields and functional architecture in two nonstriate visual areas (18 and 19) of the cat. $J$. Neurophysiol. 28, 229, 1965.

PRITCHARD, R. M., HERON, W., \& HEBB, D. O. Visual perception approached by the method of stabilized images. Can. J. Psychol, 14, 67, 1960.

RIGGS, L. A., \& WHITTLE, P. Human occipital and retinal potentials evoked by subjectively faded visual stimuli. Vis. Res., 7, 441, 1967. Notes

1. This work has been supported by the Nuffield Foundation, and carried out under the supervision of Dr. Paul Whittle.

2. Now at Psychology Dept., University of Sheffield, Sheffield 10, England. 